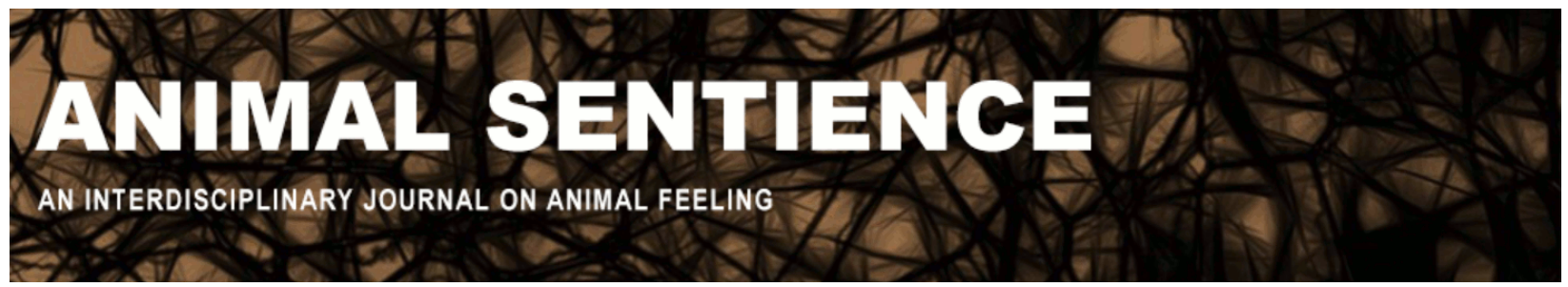

Browning, Heather (2019) What should we do about sheep? The role of intelligence in welfare considerations. Animal Sentience 25(23)

DOI: $10.51291 / 2377-7478.1460$

Date of submission: 2019-05-27

Date of acceptance: 2019-06-04 (c) 


\title{
What should we do about sheep? The role of intelligence in welfare considerations
}

Commentary on Marino \& Merskin on Sheep Complexity

\author{
Heather Browning \\ School of Philosophy \\ Australian National University
}

\begin{abstract}
Marino \& Merskin (2019) demonstrate that sheep are more cognitively complex than typically thought. We should be cautious in interpreting the implications of these results for welfare considerations to avoid perpetuating mistaken beliefs about the moral value of intelligence as opposed to sentience. There are, however, still important ways in which this work can help improve sheeps' lives.
\end{abstract}
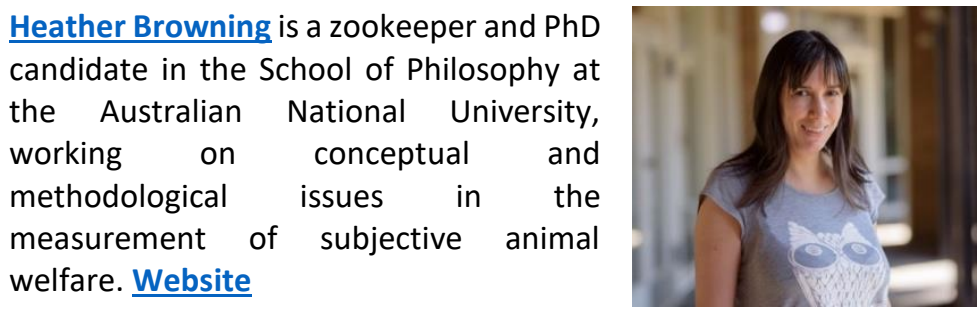

Marino \& Merskin (2019) (M\&M) review the research on sheep intelligence to make a convincing case that sheep are far more sophisticated cognitively than they are typically given credit for. They have well-developed capacities for (among others) memory, learning and social behaviour. In this, M\&M certainly succeed in their aim of compiling evidence to overturn popular stereotypes of sheep as simple and unintelligent. There is a worry, however, that the effort might be misdirected towards the wrong aim.

M\&M are almost certainly right in arguing that people tend to rank animals according to a scala naturae in which nonhuman animals are ordered on the characteristics valued by us hence on their similarity to us - and that this strongly influences how we treat animals. If we adopt this as the basis of our value system and want to improve the treatment of sheep, it makes sense to try to show that sheep have these "valuable" characteristics and thus deserve better treatment. However, this still endorses the idea that our treatment of animals should rely on their intelligence. Although M\&M are probably right that this is how many people make their moral decisions today (see also Broom 2010, Mendl \& Paul 2004), it is not the case that they should do so. Research like this might convince people to change their treatment of animals, given their current value systems (although Davis 2019 might be right that even this is unlikely); but it is arguably more important to work on changing people's value systems. What if the research had not shown that sheep were particularly complex cognitively? What if the popular conception had been borne out, and sheep were shown to be simple-minded. Should we then allow ourselves to continue to dismiss them? Intuitively, no. They are still sentient animals, with feelings that matter; and it is on this basis that we should be making our moral decisions. 
Most commonly accepted accounts of animal welfare and moral status do not consider intelligence to be the morally relevant characteristic. Rather, they say that sentience, or the ability to experience positive and negative affective states, is what we should be concerned with (e.g., Dawkins 1980, Mellor 2016, Singer 1995). Going back to Bentham (1879): "the question is not, Can they reason? nor, Can they talk? but, Can they suffer?" (p. 309). Intelligence, or cognitive complexity, is not even a good guide to sentience; the link is a tenuous one and has been widely criticized (e.g., Dawkins 2001, Mendl \& Paul 2004). This is well captured by Dawkins (2001): "you don't need to be very clever to feel pain or hunger or fear. Negative emotions that we refer to as suffering are not particularly intellectual" (s27). Demonstrating the ability to feel, as M\&M do in Section 6, is far more important in welfare considerations than demonstrating the ability to think.

This does not mean that the work reviewed by $M \& M$ is not useful. Establishing the cognitive capacities of sheep in this way can still provide a benefit, in two different ways. First, as also suggested by Horback (2019), it tells us something about how to consider the welfare of sheep. When considering welfare, we need to think about which conditions are better or worse for the animals. They will depend highly on the features of the individuals and species, such as their tolerance for particular environmental conditions, diet, and social behaviour. Cognitive abilities also play a role in determining what kinds of cognitive and behavioural challenges are required in the environment to provide appropriate mental stimulation, such as behavioural enrichment (Bekoff 1994, Mendl \& Paul 2004). Learning and memory will play a role in determining how animals process stimuli and therefore whether they find them pleasant or aversive (Duncan \& Petherick 1991). Evidence for individuality also gives us reason to consider the preferences of individual sheep in their treatment, perhaps by giving them a choice over different conditions, rather than applying a blanket condition to all of them. M\&M's evidence can also help influence how those working directly with sheep - stockpeople and handlers - respond to and interact with their animals, leading to measurable improvements in animal behaviour, health, and reproduction (Hemsworth \& Coleman 2010).

Research on animal cognition and intelligence is valuable for improving animal welfare, but we should ensure we are using it in the right way, not perpetuating erroneous beliefs or values. It is animal feelings, rather than intelligence, that ground our moral concern.

\section{References}

Bekoff, M. (1994). Cognitive ethology and the treatment of non-human animals: How matters of mind inform matters of welfare. Animal Welfare 3: 75-96.

Bentham, J. (1879). An introduction to the principles of morals and legislation. London: T. Payne \& Son.

Broom, D. M. (2010). Cognitive ability and awareness in domestic animals and decisions about obligations to animals. Applied Animal Behaviour Science 126: 1-11.

Davis, H. (2019). Our disparaging view of sheep is indeed based on cognitive inadequacy: Unfortunately, it's ours. Animal Sentience 25(20)

Dawkins, M. S. (1980). Animal suffering: The science of animal welfare. London: Chapman and Hall.

Dawkins, M. S. (2001). Who needs consciousness? Animal Welfare 10: s19-29. 
Duncan, I. J., \& Petherick, J. C. (1991). The implications of cognitive processes for animal welfare. Journal of Animal Science 69: 5017-5022.

Hemsworth, P. H., \& Coleman, G. J. (2010). Human-livestock interactions: The stockperson and the productivity of intensively farmed animals. Oxford: CABI.

Horback, K. (2019). Applied cognition research to improve sheep welfare. Animal Sentience 25(18)

Marino, L., \& Merskin, D. (2019). Intelligence, complexity, and individuality in sheep. Animal Sentience 25(1)

Mellor, D. J. (2016). Updating animal welfare thinking: Moving beyond the "Five Freedoms" towards "A Life Worth Living". Animals 6: 21.

Mendl, M., \& Paul, E. S. (2004). Consciousness, emotion and animal welfare: insights from cognitive science. Animal Welfare. 13: s17-25.

Singer, P. (1995). Animal liberation (2nd ed.). London: Plimlico. 